\title{
Atmospheric Air -the Effective Source of Low-Grade Thermal Energy for Heat Pump Snow Melting Systems under Climatic Conditions of Moscow
}

\author{
Vasilyev G.P. ${ }^{a, 1}$, Leskov V.A. ${ }^{\text {b, } 1,2}$, Mitrofanova N.V. ${ }^{c, 1}$, Gornov V.F. ${ }^{\text {d, } 1}$, Kolesova M.V. e, 2 , Yurchenko I.A. ${ }^{\text {f, } 2}$, Filippov M. \\ D. ${ }^{9,2}$ \\ 1 JSC "NIIMosstroy", Moscow, Russia \\ 2 JSC "INSOLAR-ENERGO", Moscow, Russia
}

\begin{abstract}
The article presents the results of field experimental studies to evaluate effectiveness of heat pump snow melting systems use under climatic conditions of Moscow. The studies were conducted on a mock-up near-house heat pump snow melting site using low-grade atmospheric air heat. Experimental studies carried out in field conditions confirmed feasibility and efficiency of using atmospheric air as a source of low-grade heat for evaporators of heat pump snow melting systems under climatic conditions of Moscow.
\end{abstract}

\section{Introduction:}

The most effective solution to the problem of snow removing from streets in wintertime in large northern cities is widespread use of heat pumps snow melting sites, evenly distributed across the city (for example, located in house yard territories), and using renewable energy sources (RES) as a low-grade heat source. Advantages of applying energy-saving technologies in snow melting are associated not only with significant reductions in energy consumption, but also with environmentally clean energy supply technology. Moreover, it can provide new opportunities for making snow melting systems more autonomous [1]. In the near future these features can become crucial for large cities. Eventually, heat pump snow melting systems can be integrated in technical systems and structures of buildings [2].

The key factor determining the efficiency of nearhouse heat pump snow melting sites is intensity of heat exchange between the surface of the site and the melting snow. The search for optimal parameters of these processes: temperature modes of heated surface of the site, distance between the heating pipes, rational slope of the site surface and more was the subject of many studies $[3,4]$ The studies [5] showed a significant influence of

f Corresponding author: iyurchenko@insolar.ru;

aGPVassiliev@mail.ru,

binsolar-lv@mail.ru,

cmnb577@yandex.ru,

Insolar-invest@yandex.ru,

eco-insolar@mail.ru,

gfilippovmikhail@mail.ru capillary effect in porous snow that actually determines heat and mass transfer in snow layer, bordering the heated surface.

Efficiency of heat exchange processes on the heated surface gets particular importance for heat pump sites, mentioned in this article, intended not to remove snow from the site but to melt the snow pack laid on the surface. Frost forming on the surface of the heat pump's evaporator influences its operation. This should be considered while examining effective use of near-house heat pump snow melting sites. Factors, determining icing of heat exchanger surfaces, as well as the ways of solving such problems, are considered in study [6].

\section{Experimental research:}

Experimental research on the efficiency of heat pumps snow melting systems under climatic conditions of Moscow were carried out on mock-up near-house heat pump snow melting site, which uses ambient air as a source of thermal energy.

Mock-up sample has following parameters: heated surface area of 10 square meters, capacity of 15 cubic meters of snow with density of $300 \mathrm{~kg} / \mathrm{m} 3$ per day. Advantages of such near-house heat pump snow melting 
site include quiet operation, easy maintenance, rigid design and opportunity to use it in summer as a parking lot. Photo of the mock-up near-house heat pump snow melting site using ambient air heat is shown in Figure 1.

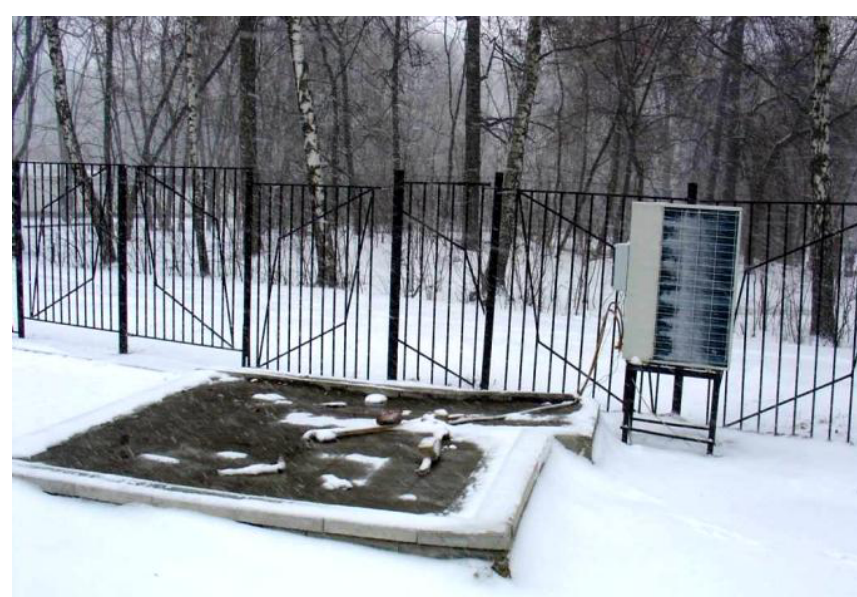

Figure 1. Mock-up near-house heat pump snow melting site using ambient air heat.

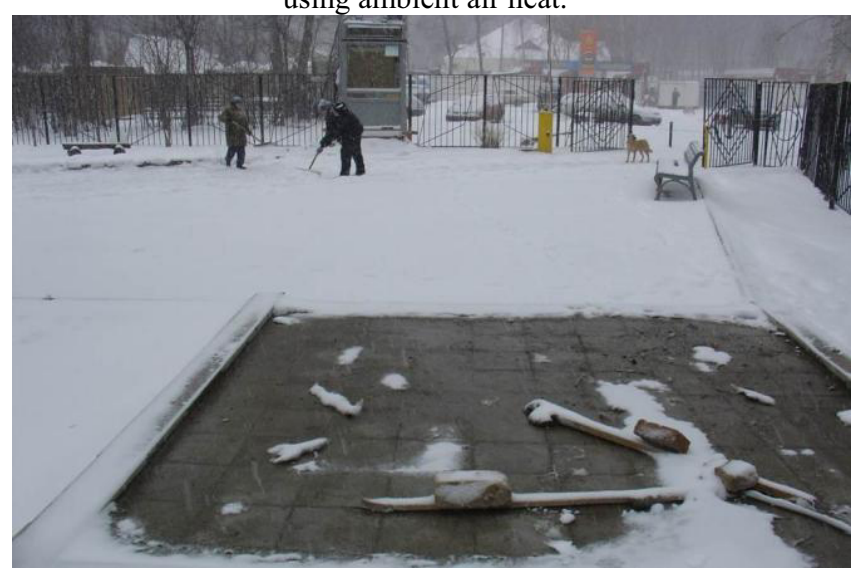

Figure 3. Operation of the unit during snowfall - operation under nominal condition.

Photos shown in Figures visualize operation of heat pump snow melting site. Figure 2 clearly shows visible thermal traces of embedded pipelines (no snow over them), Figure 3 demonstrates already warmed up area, the surface temperature equalized and all the snow has
Figure 2 shows a photo of a heat pump snow melting site operation during its heat-up, and Figure 3 illustrates operation of the unit during snowfall - operation under nominal condition. Figure 4 shows the air-source heat pump unit with snow and frost on its evaporator.

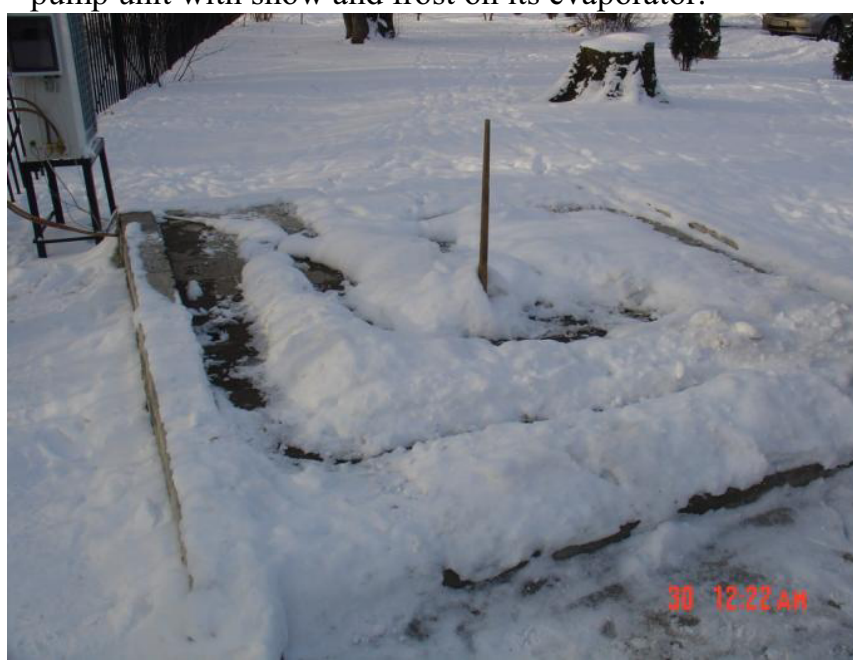

Figure 2. The heat pump snow melting site operation during its

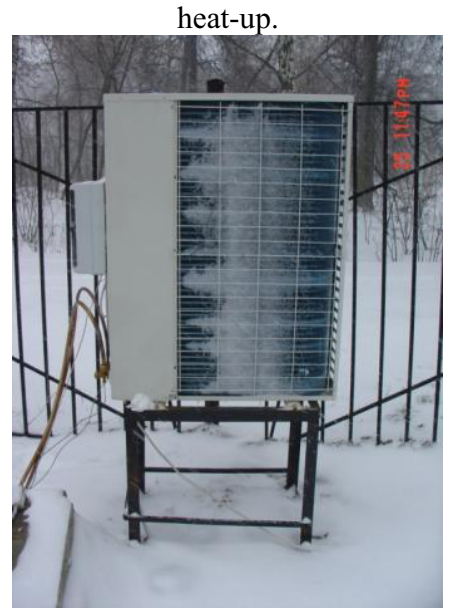

Figure 4. The air-source heat pump system using ambient air heat under nominal operating condition.

melted, and Figure 4 shows the freezing of the evaporator of the heat pump. To remove frost system switches over to "defrost" mode for 2 - 3 minutes, switching frequency depends on air humidity and temperature.

Figure 5 summarizes the results of field studies. 


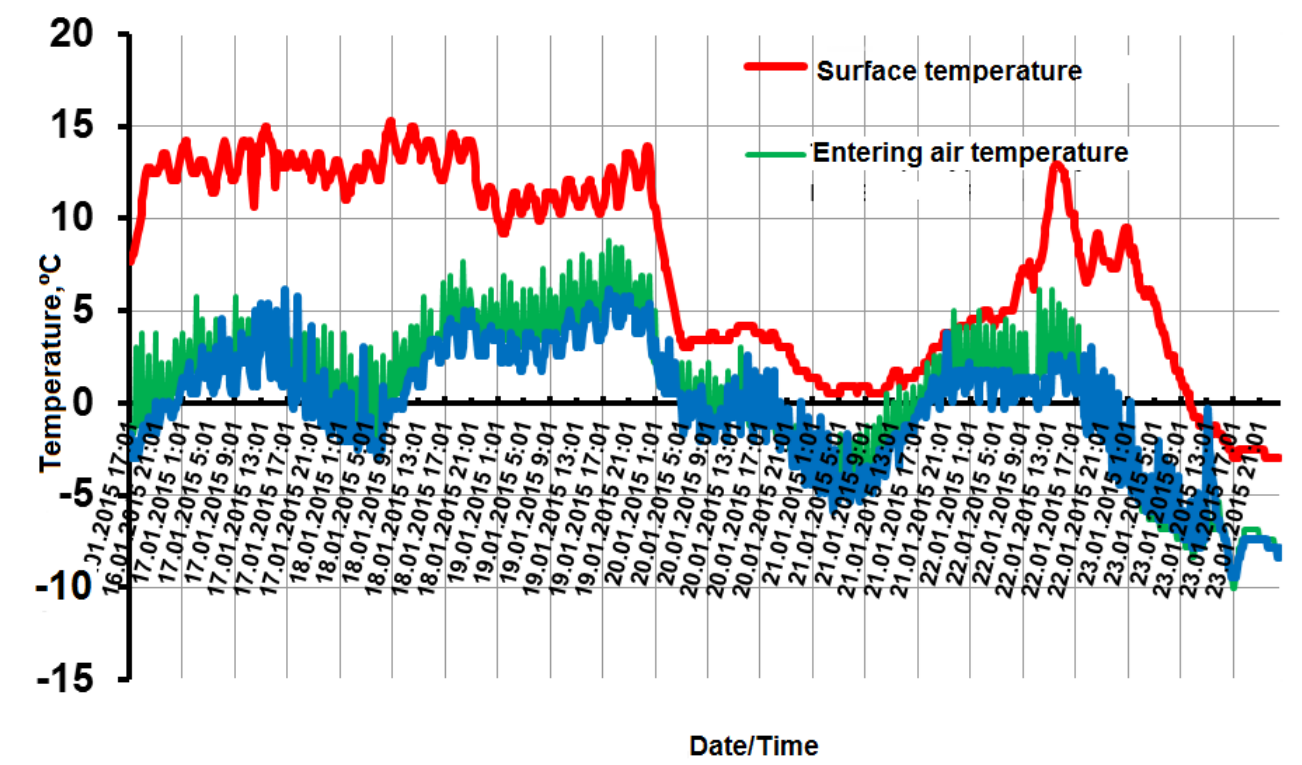

Figure 5. Temperatures of site surface (red) and air before (green) and after (blue) evaporator.

Field experimental studies were aimed at full-scale testing of newly developed technical and technological solutions for the use of ambient air as a source of lowgrade heat for heat pump snow melting sites. The fullscale approbation results of the experimental site are quite positive. For the entire experiment time (three winter months) it coped with its function: surface temperature was always above zero and snow melting was provided. Essential outcome of the studies is the fact that the possibility and efficiency of air usage as the lowgrade heat energy source for heat pump snow melting systems in Moscow are demonstrated. Preliminary doubts associated with low ambient temperatures in winter in Moscow, frost formation on evaporators, etc. have been partially proved wrong, and partially found out have been technical resolutions for such challenges. Snow in Moscow during severe frosts is observed rarely. This circumstance allows effective use of the outdoor air as a heat source for heat pump snow melting systems. The average COP value of heat pump during the experiment was 2.65 , meaning that per $1 \mathrm{kWh}$ of energy consumed $2.65 \mathrm{kWh}$ of heat energy was produced. The problems of evaporators icing have been resolved by reversing heat pump cycle into the "defrost" mode; as for snow build-up on evaporators selected have been pertinent fans and distances between the evaporator fins ensuring the decrease of this effect influence.

\section{Summary:}

Field tests results confirmed feasibility and effectiveness of ambient air use as a low-grade heat source for heat pump snow melting systems under Moscow climatic conditions. Preliminary doubts associated with low ambient temperatures in winter in Moscow, frost formation on evaporators, etc. have been partially proved wrong, and partially found out have been technical resolutions for such challenges. Snow in Moscow during severe frosts is observed rarely. This circumstance allows effective use of the outdoor air as a heat source for heat pump snow melting systems. The average COP value of heat pump during the experiment was 2.65 , meaning that per $1 \mathrm{kWh}$ of energy consumed $2.65 \mathrm{kWh}$ of heat energy was produced.

\section{Acknowledgements:}

The Research was conducted by JSC "NIIMOSSTROY" with the financial support of the Ministry of Education and Science of Russia. Unique identifier of the project RFMEFI57914X0081.

\section{References:}

1. Koretskiy V.E. Moscow snow removal system capacity development options. Ecology and industry of Russia 2005. - April. - P. 8-10.

2. Takeuchi $\mathrm{M}$ et al. Development and numerical simulation of geothermal snow-melting method using foundation pile. Trans Soc Heating, AirConditioning and Sanitary Eng Jpn 1993;52:59- 69.

3. Chapman, W.P., 1952. Design of snow melting systems. Heating and Ventilating 49 (4), 96-102.

4. Colbeck, S., 1982. An overview of seasonal snow metamorphism. Reviews of Geophysics and Space Physics 20 (1), 45-61.

5. Coleou, C., Lesaffre, B., Brzoska, J., 1999. Capillary rise in snow. Hydrological Processes 13 (12-13), 1721-1732.

6. Vasilyev G.P. Dmitriev, A.N., Timofeev N.A., Korolkova N.V., Yurchenko I.A. «Study on formation and freezing of condensate in heat exchangers for recuperation or utilization of exhaust air low-grade heat", Energetik 11, 2013 